PF 2019 (LXXIV): 393-400

\author{
MARIA TRAWIŃSKA \\ Instytut Slawistyki Polskiej Akademii Nauk \\ ul. Bartoszewicza 1b m. 17 \\ 00-337 Warszawa \\ tel. +48228267688 \\ e-mail: maria.trawinska@ispan.waw.pl
}

\title{
WYRAZY POLSKIE W VARIAE EXHORTATIONES ET FORMULAE ORDINIS FRATRUM MINORUM DE OBSERVATIA BARTŁOMIEJA Z BYDGOSZCZY
}

SŁOWA KLUCZOWE: Bartłomiej z Bydgoszczy, XVI-wieczny rękopis, łacina, polskie glosy.

KEYWORDS: Bartholomeus de Bydgostia, manuscripts, $16^{\text {th }}$ century, Latin, Polish glosses.

\section{POLISH WORDS IN VARIAE EXHORTATIONES ET FORMULAE ORDINIS FRATRUM MINORUM DE OBSERVATIA BY BARTHOLOMEUS OF BYDGOSZCZ}

\begin{abstract}
The article discusses the $16^{\text {th }}$-century Latin manuscript by Bartholomeus of Bydgoszcz, which was a handy notebook containing various exhortations and convent forms. In a very different way, he noted in it almost two hundred Polish words. The ambiguous Latin words were juxtaposed with ambiguous Polish equivalents, and the closeness of some records appears next to entries loosely related. Many entries on the margins are difficult to combine with the main text. For this reason, we cannot determine the meaning for all the words. The presence of the Polish language, mostly in the form of loose expressions and individual words, testifies to the fact that in the relationship of interest to us, the Polish language is more alongside the Latin text than in the text.
\end{abstract}

Tytułowy rękopis znajduje się w Bibliotece Czartoryskich w Krakowie (syg. 3795). W inwentarzu odnotowano tylko, że jest to zabytek łaciński liczący 336 stron, który powstał pomiędzy XV a XVI wiekiem ${ }^{1}$. W badaniach naukowych

\footnotetext{
1 http://mnk.pl/oddzial/biblioteka [dostęp 1.12.2018].
} 
po raz pierwszy został uwzględniony prawie sto lat temu, kiedy to Kamil Kantak podjął trud opracowania historii bernardynów w Polsce, ze szczególnym uwzględnieniem prowincji bydgoskiej. Autor wskazał, że rękopis zawiera różne formularze klasztorne, wyciągi z dzieł teologicznych oraz kazania dla braci zakonnych. Zaznaczył również, że zamieszczona informacja o Bartosławie z Bydgoszczy nie daje podstaw do przypisania mu autorstwa książki (Kantak 1933).

Ponowne zainteresowanie rękopisem łączy się z rozpoczęciem przez Irenę Kwilecką i Hannę Popowską-Taborską prac nad słownikiem Bartłomieja z Bydgoszczy. Uwaga badaczek skupiła się głównie na występującej w nim polszczyźnie, którą cechuje „charakterystyczna dla autora pisownia”, a zakwestionowany przez Kantaka zapis: Consumatum est per fratrem Barthoslaum Bydgostianum, fratrem ordinis Minorum 1520 (k. 294) stała się podstawą włączenia Variae... do spuścizny bydgoskiego zakonnika i doprecyzowania daty powstania. Dodatkowym argumentem przemawiającym za jego autorstwem była:

analiza pisma i porównanie tej książki z innymi rękopisami Bartłomieja, jak również w oparciu o skrupulatną analizę zawartości rękopisu możemy stwierdzić bez najmniejszej wątpliwości, że cały ten rękopis (poza paroma krótkimi tekstami dopisanymi późniejszą ręką na ostatnich kilku stronach) napisany został ręką Bartłomieja z Bydgoszczy (Kwilecka, Taborska 1977: 12).

Wskazanie autorstwa nie zaowocowało dalszymi pracami nad zabytkiem. Mimo włączenia go do spuścizny Bartłomieja i zasygnalizowania obecności polskich glos, które odebrano jako „wyraźny wzrost jego zainteresowania językiem polskim" (Kędelska 1997: 14), nadal pozostaje nierozpoznany. Rękopis jest niewielką książką (w przybliżeniu odpowiada współczesnemu formatowi B7), która ze względu na swoją zawartość i cechy zewnętrzne określana jest mianem Manuale Guardiani Bydgostiensis. Starannie prowadzone zapiski z rubrowanymi tytułami przechodzą w bardzo pospiesznie sporządzane notatki, które są uzupełniane luźnymi uwagami i komentarzami wpisywanymi w wolne miejsca. Dopiski te powstawały w różnym czasie, o czym świadczy zmieniający się odcień atramentu i zacięcie pióra.

Manuskrypt spisany jest odmianą pisma, która ma już cechy kursywy humanistycznej, nazywanej także italikąa 2 Zaliczyć można do nich przede wszystkim wyraźne oddzielanie wyrazów, obecność prostego d, dążność do odznaczania i kropką lub kreską, okrągłe r. Dość licznie poświadczone są jeszcze formy typowe dla kursywy gotyckiej, takie jak upraszczanie kształtów liter oraz dążność do pisania kilku znaków jednym pociągnięciem pióra, która powoduje dekompozycję graficzną utrudniającą identyfikację liter. Obecne jest długie $\int$, bardzo często c i t są tożsame graficznie, litera $\mathbf{u}$ na początku wyrazu ma formę spiczastą, czyli jest

2 Szerzej na ten temat: Battelli 1999, Cencetti 1977, Semkowicz 2007. 
tożsama z literą v. Nadal obecne są ligatury, a łacińskie zapisy obfitują w abrewiacje. Widoczna jest także swoboda w operowaniu majuskułą.

Pismo sprawia wrażenie niezbyt starannego, miejscami wręcz brulionowego. Uwaga ta odnosi się nie tylko do polskich zapisów, które Bartłomiej kreślił wyjątkowo drobnym pismem. W analogiczny sposób dopisywał również łacińskie wyrazy. Kompozycja rękopisu, sposób wprowadzania zapisek oraz charakter pisma powodują, że nie zawsze łatwo jest odczytać i połączyć dopisany w wolnym miejscu wyraz z jego łacińskim odpowiednikiem.

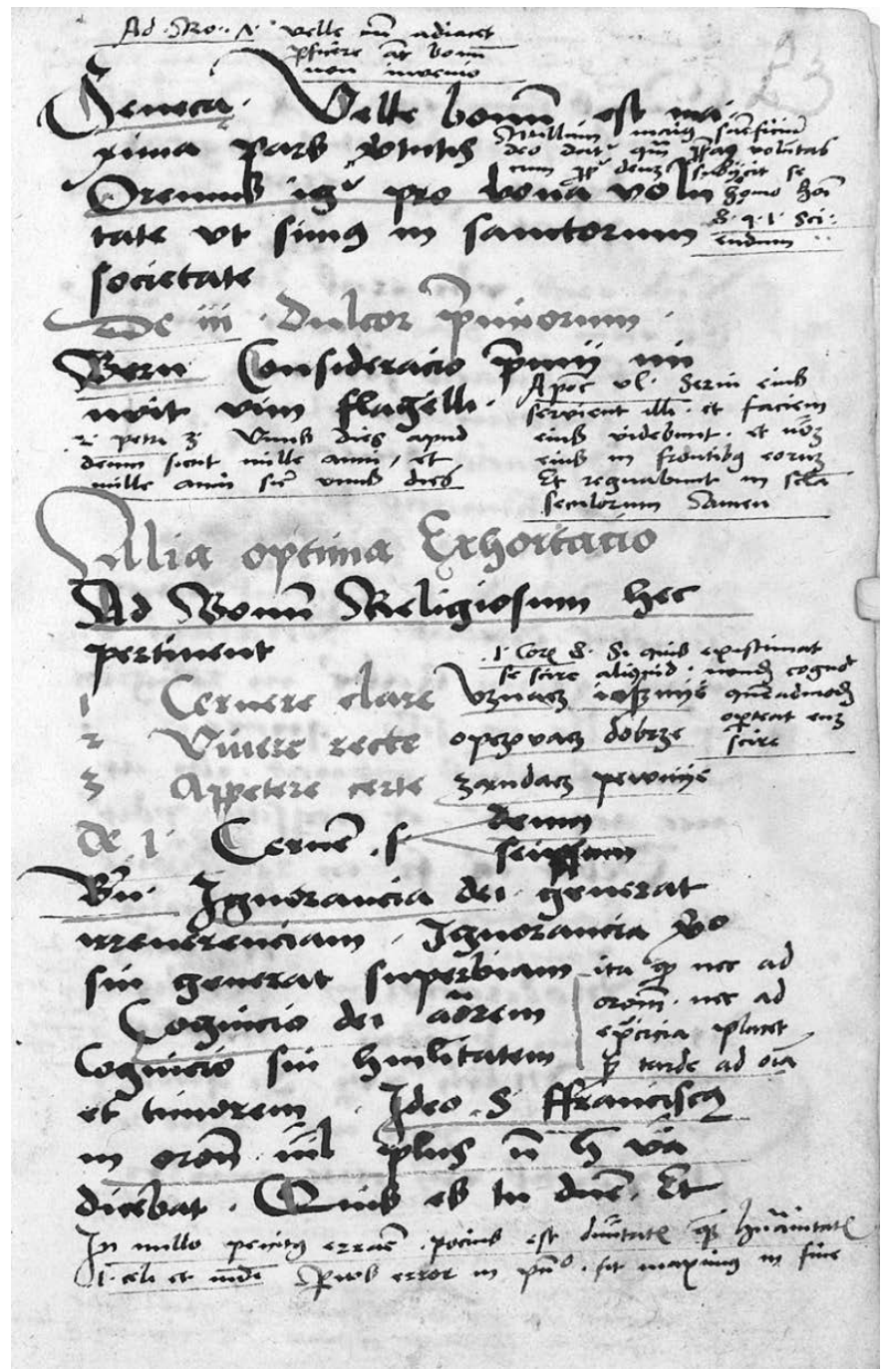

Karta 23 (skala 1:1) 
Szczegółowa analiza rękopisu potwierdziła obecność prawie dwustu polskich wyrazów, których rozmieszczenie jest nierównomierne - fragmenty nasycone nimi sąsiadują z kartami, na których nie odnajdujemy żadnego. Polszczyznę wprowadzał Bartłomiej na dwa sposoby, jeden polega na umieszczaniu polskich zwrotów pod łacińskimi odpowiednikami, w drugim poprzestawał na dopisywaniu pojedynczych wyrazów, zwykle w interlinii, także na marginesach, niekiedy między szpaltami.

W artykule, dla przybliżenia charakteru zapisów cytujemy i omawiamy tylko wybrane przykłady, które można podzielić na dwie grupy. Do pierwszej zaliczamy zwroty występujące w ekshortacjach:

k. 12

Ideo $\iint u n t$ Exhortationes in religione noftra: pro

Conservandis moribus dlÿa dobrich obiczayow zachowanÿa

Vitandis $\int c e l e r i b u s$ dla grzechow vvyarovanÿa

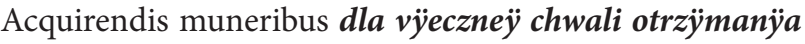

k. 16

Exhortationes fiunt Ad:

Precavendam culpam dlya vvyarovanya grzechow

Inferendam penam Skaranya viftąmpow

Obtinendam gloriam doftampyenya chvaly $z$ dobrich vczynkow

Divina providentia omnes dirigit rządzi quosdam erigit... wSpomaga ut Petrum...

k. 21

Alia Exhortatio

Ista conservant religiosum

Vigor preceptorum przikazanya cya $\iint k o \int c z, v a z n o \int c z$

Splendor exemplorum Swyąntich przicladnofcz

k. 23

Alia optima Exhortatio

Ad Bonum Religiofum hec pertinenten

Cernere clare vznacz ia $\boldsymbol{z}$ znye

Vivere recte opczovacz dobrze

Appetere certe zandacz pewnye

k. 28

In religione enim dominus bono et fimplici fratri dat:

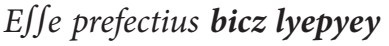

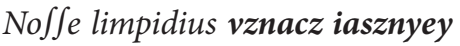

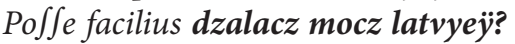

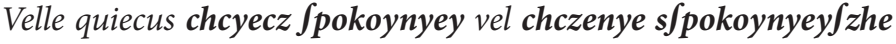

k. 45

Ergo fimus Sicut Sancti fratres qui fuerunt In

Sapientia profundifsimi 


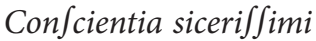

Obedientia promitifsimi

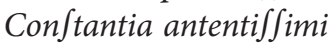

k. 84

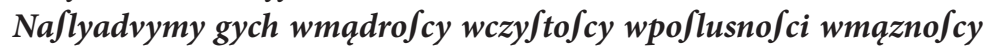

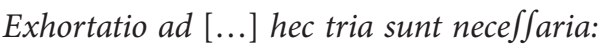

Humilitas in intelectu rozvm pokorny

Puritas in affectu vmy ll czifty

Veritas in effectu vczynek profty

k. 101

Exhortatio pro electionem difcreti ad capitulum provinciale

Campana pulfata eft in refectorio

Littera est allata... collegio

Forma eius erit publicata nece $\iint a$ ario ut impleamus pr... mandata cum dei adiutorio

Ve zwonek zwonyono

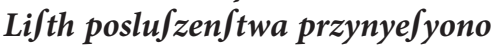

Potrzeb aby gy czczyono aby przikazanye bylo vipelnyono

k. 102

Hic tria miSteria

Nodum vazel trudny

Modum obiczai rząndny

Fructum vzitek pewny a potrzebny

Drugą grupę tworzą pojedyncze wyrazy dopisywane w obrębie różnych zapisek i formularzy:

k. 241 US travyene vzytek

k. 243 Utenfilia rzeczy domowe

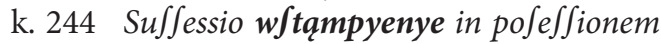

k. 245 Reditus dochody

k. 247 Execucio vypelnyenye

k. 247 Executor opyekvn vicyagacz

k. 254 Mutuare wzayem dacz

k. 254 Mutuum zaÿemne danye pozyczki

k. 254 Commodare poziczycz

k. 255 Comodatum la lkave poziczenye

k. 255 Se obligare Slÿvbovacz

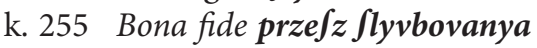

k. 255 Impignorare zastavicz

k. 256 Locare operas Juas naymovacz

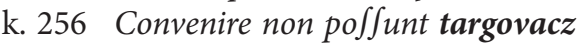

k. 256 Locacio nayem

k. 266 Adminiftrator rząncza

k. 266 Adminiftracionem Jzafovanye 
W dotychczasowych opracowaniach polskie wyrazy w łacińskich zabytkach są określane mianem glos, co pośrednio wskazuje, że odbierane są jako objaśnienie czy też tłumaczenie trudnych miejsc. Podkreśla się również, że kontekst łaciński pozwala „ściśle ustalić znaczenia wyrazów” (Wydra, Rzepka 2006: 197). Z tego względu uważane są za bardzo cenny materiał do badań leksykalnych (Belcarzowa 1981-2001: 17).

Analiza relacji łacińsko-polskich odsłoniła nie tylko ich złożoność, ale także trudności związane z opisem. Charakter rękopisu wskazuje, że nie jest on efektem systematycznej pracy Bartłomieja. Dopiski były wprowadzane okazjonalnie, raczej bez uwzględniania tego, co znajdowało się już na innych kartach.

Zapis dla grzechow vvyarovanÿa 'unikanie grzechów' (k. 12) występuje powtórnie na dalszych kartach: dlya vvyarovanya grzechow (k. 16). Pierwszy poprzedzony jest łacińskim vitandis $\int$ celeribus, przy drugim widnieje precavendam culpam. Odmienne wyrażenia, z których jedno mówi o 'uniknięciu występków', kolejne o 'zapobieganiu winom', Bartłomiej objaśnia tak samo. Łacińskie 'unikanie' i 'zapobieganie' zastąpił 'uwiarowaniem', natomiast 'występek i 'wina' są tożsame z 'grzechem'.

W tym samym fragmencie zrobił uwagę o 'zachowaniu dobrych obyczajów' - dlÿa dobrich obiczayow zachowanÿa (k. 12), w innym miejscu wskazał, że obyczaj powinien być 'rządny' obiczai rząndnÿ (k. 102). Określenie to pojawia się również w kontekście 'obyczaju prawa duchowego' - podlug obiczayv prava duchownego (k. 104). W pierwszym zapisie 'obyczaj' jest dosłownym tłumaczeniem łacińskiego moribus, w drugim modus to bardziej 'przepis, reguł, sposób', natomiast w zwrocie societatem Servata forma canonica, słowo to nie występuje, Bartłomiej dodał je w podanym przez siebie objaśnieniu. Zapisy te odczytujemy również jako formę komentarza, w którym dodał, że obyczaj powinien być dobry i rządny.

Przykładów różnych dopowiedzeń jest więcej. Objaśniając obtinendam gloriam czyli 'dostąpienie chwały' dodaje, że warunkowane jest ono dobrymi uczynkami: doftąmpyenya chvaly $z$ dobrich vczynkow (k. 16). Tłumacząc nodum vązel trudnÿ (k. 102) dopisuje przymiotnik trudny, jest to najprawdopodobniej forma doprecyzowania znaczenia poprzez wskazanie, że rzeczownik nodus oznacza także 'trudność, przeszkodę'. Powtarzający się trzykrotnie zapis 'użytek' u us uzytek (k. 70), fructum vzitek pewny a potrzebny (k. 102), ufus travyene vzytek (k. 241) łączy z usus i fructis. W łacinie są to wyrazy wieloznaczne, podobnie jak wskazany przez Bartłomieja polski odpowiednik. Tak lapidarny zapis jest bardzo trudny do objaśnienia. Dopowiedzenie, że chodzi o coś 'pewnego a potrzebnego' w połączeniu z 'trawieniem', wskazuje jakieś 'korzyści, dochody', które są potrzebne i mogą być też trawione, czyli 'wydawane'. Połączenie użytku z trawieniem jest również przykładem dopisywania polskich wyrazów na zasadzie 
asocjacji, w której korzyść łączy się $\mathrm{z}$ wydawaniem. W mutuus zä̈emne danye pozyczki (k. 254) wzajemny jest skojarzony z dawaniem pożyczki.

Odosobniony przykłady vires $\int z \ddot{y} l \ddot{y}(\mathrm{k} .12)$ jest najprawdopodobniej zapiską o charakterze gramatycznym. Obok rzeczownika vis podanego w $\mathrm{lm}$. Bartłomiej umieścił również w $\mathrm{lm}$. polski odpowiednik.

W rękopisie występują również dłuższe frazy, których nie można nazwać tłumaczeniami, np.: w Longani(mi)tate obtinetur Janctorum copula, czyli 'wytrwałością objętą więź ze świętymi' łączy z dobrą nadzieją na oczekiwanie towarzy-

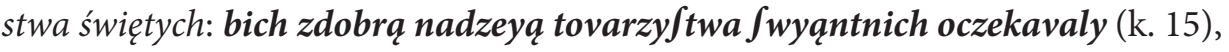
natomiast Acquirendis muneribus 'otrzymanie zasług' to innymi słowy otrzyma-

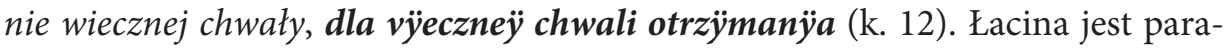
frazowana przez Bartłomieja na gruncie własnej konwencji, co może wynikać $\mathrm{z}$ dostosowywania do potrzeb kaznodziejskich czy też innych potrzeb wewnętrznych zgromadzenia zakonnego, w którym działał.

Wskazane przykłady ilustrują, że wprowadzanie polszczyzny może przybierać: formę dosłownego tłumaczenia, być zbliżonym znaczeniowo dopowiedzeniem, rozbudowanym komentarzem lub swobodną parafrazą. Wieloznaczny wyraz łaciński można zestawić $\mathrm{z}$ równie wieloznacznym polskim słowem, a bliskość znaczeniowa jednych zapisów występuje obok zapisek luźno powiązanych znaczeniowo. $\mathrm{Z}$ tego powodu nie dla wszystkich wyrazów można dziś precyzyjnie ustalić znaczenie. Dla Bartłomieja znającego realia, które opisywał i środowisko, do którego kierował swoje wskazania, kwestia ta nie istniała, natomiast z naszej perspektywy jest to w znacznym zakresie nierozwiązywalny problem. Obecność języka polskiego przeważnie w postaci luźnych wyrażeń i pojedynczych słów poświadcza, że w interesującej nas relacji polszczyzna występuje bardziej obok tekstu niż w tekście.

Manuskrypt Varie... z pewnością nie jest czystopisem z klarownym zamysłem redakcyjnym, lecz zbiorem brulionowych zapisek. Ma to oczywiście swój walor, pozwala ukazać warsztat pracy XVI-wiecznego skryby, ale niezwykle utrudnia opracowanie zabytku. Dodatkową komplikacją jest zawartość rękopisu, w którym ekshortacje przeplatają się z różnymi formularzami i dokumentami klasztornymi. Determinuje to charakter polskich wpisów, w których dla przykładu Sandalia Sandaly (k. 273) przeplatają się z Iure polii divino pravem bozym (k. 221), a Tribunus rothmystrz (k. 333) z uten filia rzeczy domowe (k. 243), utrudniając tym samym wskazanie szerszego kontekstu czy też jednorodnych kręgów tematycznych.

Aby dobrze osadzić polszczyznę, należałoby najpierw opracować szeroki kontekst łaciński, w którym powstawała i bardzo długo funkcjonowała. Badania takie są postulowane od lat. Z powodu braku takich opracowań odwołujemy się do słowników, przede wszystkim łaciny średniowiecznej, ale także łaciny klasycznej, 
czyli historyczne zapisy o charakterze słownikowym porównujemy z materiałem zawartym we współcześnie redagowanych słownikach historycznych, co nie jest w pełni satysfakcjonująca metodą, ale na tym etapie dostępną.

\section{Bibliografia:}

Battelli Giulio, 1999, Lezioni di paleografia, wyd IV, Vaticano.

Belcarzowa Elżbieta, 1981-2001, Glosy polskie w łacińskich kazaniach średniowiecznych, cz. I-IV, Kraków, http://rcin.org.pl/ijp/dlibra/publication?id=15963\&from=pubindex\&dirids $=80 \& t a b=1 \& l p=165$ [dostęp 1.03.2019].

Cencetti Giorgio, 1977, Lineamenti di Storia della scrittura latina, wyd II, Bologna.

Géhin Paula (red.), 2008, Jak czytać rękopis średniowieczny, Warszawa.

Jougan Alojzy, 2013, Słownik kościelny łacińsko-polski, wyd. V, Sandomierz.

Kantak Kamil, 1933, Bernardyni polscy, t. I, 1453-1572, Lwów.

Kędelska Elżbieta, 1997, Przydatność łacińsko-polskich wokabularzy do badań językoznawczych - zalety i ograniczenia, [w:] Leksyka słowiańska na warsztacie językoznawcy, red. Hanna Popowska-Taborska, Warszawa, s. 117-125.

Kędelska Elżbieta, Kwilecka Irena, Łuczak Arleta, 1999-2012, Słownik Bartłomieja z Bydgoszczy. Wersja polsko-łacińska, t. I-V (A-St), Warszawa.

Korpanty Józef (red.), 2001, Słownik łacińsko-polski, t. 1-2, Warszawa.

Kwilecka Irena, Popowska-Taborska Hanna, 1977, Bartłomiej z Bydgoszczy, leksykograf polski pierwszej połowa XVI w., Wrocław.

Plezia Marian (red.), 1953-2010, Słownik łaciny średniowiecznej w Polsce, t. 1-8, Wrocław. Popowska-Taborska Hanna (red.), 1979, Bartłomiej z Bydgoszczy i jego dzieło, Warszawa. Rękopis Variae exhortationes et formulae ordinis Fratrum Minorum de Observatia, syg.

3795, Biblioteka Czartoryskich w Krakowie.

Semkowicz Władysław, 2007, Paleografia łacińska, wyd. 2, Kraków.

Wydra Wiesław, Rzepka Wojciech R. (oprac.), 2004, Chrestomatia staropolska. Teksty do roku 1543, Wrocław.

\section{Streszczenie}

Artykuł omawia wyrazy polskie występujące w XVI-wiecznym łacińskim rękopisie Bartłomieja z Bydgoszczy. Wskazane przykłady ilustrują, że wprowadzanie polszczyzny może przybierać formę dosłownego tłumaczenia łacińskiego fragmentu, być zbliżonym znaczeniowo dopowiedzeniem lub rozbudowanym komentarzem, bądź swobodną parafrazą. 